\title{
Produção, extração e análise físico-química de pectina do bagaço de laranja através do modelo de área superficial por Box-Behnken
}

\section{Production, extraction and physicochemical analysis of orange pomace pectin by Box-Behnken surface area model}

\author{
Antonio Carlos Pereira de Menezes Filho ${ }^{1}$, Carlos Frederico de Souza Castro ${ }^{2}$ \\ ${ }^{1}$ Mestre em Agroquímica, pelo Instituto Federal Goiano, Campus Rio Verde - GO, Brasil. https://orcid.org/0000-0003-3443-4205 E-mail: \\ astronomoamadorgoias@gmail.com *Autor de correspondência \\ 2 Doutor em Química pela UnB, Professor do Instituto Federal de Educação, Ciência e Tecnologia Goiano, Campus Rio Verde -GO, Brasil. \\ https://orcid.org/0000-0002-9273-7266E-mail: carlosfscastro@gmail.com
}

\author{
Palavras-chave \\ Otimização \\ Pectina \\ Farinha mesocarpo \\ Rendimento \\ Ácido galacturônico
}

\begin{abstract}
O trabalho teve por objetivo produzir, extrair e analisar fisico-quimicamente a pectina do mesocarpo a partir do bagaço de laranja através do modelo de área superficial por Box-Behnken. O bagaço de laranja foi coletado em uma indústria de suco no município de Rio Verde, GO, Brasil. A farinha do mesocarpo foi produzida, e a extração da pectina foi realizada em diferentes concentrações de ácido cítrico, temperatura e tempo para a determinação do rendimento de massa péctica através de um delineamento composto central rotacional com quatro pontos axiais e três repetições no ponto central, totalizando 15 ensaios través do modelo matemático de Box-Behnken. A pectina produzida foi comparada com a pectina comercial através de análise titulométrica. As análises físico-químicas foram $\mathrm{pH}$, proteína e pureza. A resposta do rendimento apresentou $R^{2}=91,78 \%$, os efeitos significativos foram temperatura, tempo*tempo, ácido*ácido, ácido, tempo, ácido*temperatura, temperatura*temperatura. O modelo de Box-Behnken para pectina de laranja apresentou duas soluções, $1^{*}$ concentração ácida de 0,88 $\mathrm{Mol} \mathrm{L}^{-1}$, tempo de 59,3 min., temperatura de $40{ }^{\circ} \mathrm{C}$ com rendimento de $49,55 \% ; 2$ a concentração ácida de 0,93 $\mathrm{Mol} \mathrm{L}^{-1}$, tempo de $71,09 \mathrm{~min}$., temperatura de $40{ }^{\circ} \mathrm{C}$ com rendimento de $48,43 \%$. $\mathrm{A}$ titulometria apresentou (AUA) de 44,8\%, (MeO) de 0,7\%, (FA) de 45,4\%, (FN) 54,6\%, (GE) de 8,75\%. A Físicoquímica apresentou $\mathrm{pH}$ de 2,68 , proteína de $3,47 \%$ e pureza de $96,53 \%$. A pectina de laranja a partir da farinha do mesocarpo apresentou grau de esterificação abaixo de 50\%, sendo considerada pectina de baixo grau de esterificação. Os resultados obtidos demostraram que o modelo utilizado é adequado e eficiente para extração máxima de pectina e que apresenta uma pectina de baixo grau de esterificação, podendo ser aplicada em sucos e sheiks.
\end{abstract}

\section{Keywords}

Optimization

Pectin

Mesocarp flour

Yield

Galacturonic acid
The objective of this work was to produce, extract and physically and chemically analyzed the mesocarp pectin from orange pomace using the Box-Behnken surface area model. Orange pomace was collected in a juice industry in the city of Rio Verde, GO, Brazil. Mesocarp flour was produced, and pectin extraction was performed at different citric acid concentrations, temperature and time to determine pectic mass yield through a central rotational composite design with four axial points and three repetitions at the central point. totaling 15 trials through the Box-Behnken mathematical model. The pectin produced was compared with commercial pectin by titration analysis. The physicochemical analyzes were $\mathrm{pH}$, protein and purity. The yield response showed $R^{2}=$ $91.78 \%$, the significant effects were temperature, time*time, acid*acid, acid, time, acid*temperature, temperature*temperature. The Box-Behnken model for orange pectin presented two solutions, 1st acid concentration $0.88 \mathrm{Mol} \mathrm{L}^{-1}$, time $59.3 \mathrm{~min}$, temperature $40{ }^{\circ} \mathrm{C}$ with $49.55 \%$ yield; 2 nd acid concentration 0.93 $\mathrm{Mol} \mathrm{L}^{-1}$, time $71.09 \mathrm{~min}$., Temperature $40{ }^{\circ} \mathrm{C}$ in $48.43 \%$ yield. The titration showed (AUA) $44.8 \%$, (MeO) $0.7 \%$, (AF) $45.4 \%$, (FN) $54.6 \%$, (GE) $8.75 \%$. Physical chemistry had a $\mathrm{pH}$ of 2.68 , a protein of $3.47 \%$ and a purity of 96.53\%. Orange pectin from mesocarp flour presented esterification degree below $50 \%$, being considered low esterification pectin. The results showed that the model used is adequate and efficient for maximum pectin extraction and has a low esterification pectin and can be applied to juices and sheiks.

\section{INTRODUÇÃO}

O Brasil é o principal produtor e exportador de laranja no mundo. Sendo os estados de São Paulo e Minas Gerais os maiores produtores brasileiros (KORSTEN; TAVERNER, 2012; TASIC, 2017; MARTINS; NARDOQUE, 2020). Há inúmeras variedades de laranjas, e dentre elas, as mais comercializadas no mercado brasileiro são as variedades
Pera-rio, Hamlin, Natal, Valencia, Pineapple e Westin todas pertencentes ao grupo das laranjas doces (ZANELLA, 2013).

$O$ crescente desenvolvimento industrial de produtos beneficiados a partir dos frutos cítricos, principalmente na produção de sucos, onde geram volumosas quantidades de resíduos diariamente nas indústrias processadoras. De acordo com Rezzadori e Benedetti (2009), o resíduo produzido da laranja equivale a $50 \%$ do peso total da fruta. $O$ 
bagaço é composto basicamente por (pericarpo, mesocarpo e parte do endocarpo com sementes), parte desse resíduo é utilizado como complemento na dieta humana e/ou animal, sendo também empregado como fertilizante orgânico, na extração de óleo essencial, compostos antioxidantes e de pectinas (STORRER et al., 2017).

A laranja bem como outros frutos cítricos apresenta importante quantitativo de pectina que está associada à celulose, hemicelulose e lignina, sendo designada nesta forma de protopectina, podendo ser obtida através do mesocarpo (PAIVA et al., 2009; REN et al., 2019).

A descoberta da pectina ocorreu em 1790 por Vauquelin, e em 1824 Braconnot caracterizou este homopolímero em frutas e em resíduos de frutas e hortaliças (BRAVERMAN; BERK, 1976). A pectina é um polissacarídeo encontrado na parede celular das células vegetais, contribuindo para a adesão, firmeza e resistência mecânica principalmente nos frutos verdes e maduros (FERNANDES et al., 2014). Os monômeros de ácido D-galacturônico são ligados em cadeia a 1-4, com grau de grupos carboxilas metil esterificados variáveis, sendo constituída de $65 \%$ de ácido galacturônico (CANTERI et al., 2012; LARA-ESPINOZA et al., 2018).

O processo de extração da pectina apresenta múltiplos processos como físicos e químicos nos quais a hidrólise ácida, extração e a solubilização deste composto, são influenciados por diversos fatores como acidez, temperatura, pH e tempo (MUNHOZ et al., 2010; SABERIAN et al., 2017). As pectinas podem ser empregadas na produção e desenvolvimento de matrizes poliméricas para embalagens bioativas, onde pectinas de baixo grau de esterificação produzem géis firmes e resistentes através da ligação iônica pelas pontes de cálcio entre dois grupos carboxílicos pertencentes a diferentes cadeias próximas (Abid et al., 2017; Batista et al., 2005), bem como emulsificantes, na produção de sucos, sheiks e na fabricação de geleias (May, 1990; LIMA et al., 2017), e conferir firmeza, retenção de sabor e aroma (GANCZ et al., 2006; AMAL et al., 2016).

Existem várias formas experimentais de extração de pectina como química e enzimática (PAGÁN et al., 2001; VASCO-CORREA; ZAPATA, 2017). Mas ainda pouco se desenvolveu tecnologicamente para a criação de protocolos de extração, que apresentem o máximo de rendimento de extração deste biopolímero abundante na natureza que apresenta também, grande importância na indústria de alimentos.

Este trabalho teve por objetivo produzir, extrair e analisar a pectina a partir do resíduo do mesocarpo (bagaço) de laranja (Citrus sinensis L. Osbeck.) como alternativa para agregação de valores aos resíduos sólidos através da otimização de produção pelo modelo Box-Behnken.

\section{MATERIAL E MÉTODOS}

Os bagaços dos frutos de laranja foram coletados em uma empresa de sucos no município de Rio Verde - GO, Brasil. O material foi transportado em sacos plástico de cor preta em embalagem hermética até o laboratório de Química Tecnológica no Instituto Federal Goiano, Campus Rio Verde. Com auxílio de uma faca inox, foi retirado o mesocarpo (parte branca). Em seguida, uma solução aquosa a $1 \%$ de hipoclorito de sódio ( $/ \mathrm{v}$ ) foi acrescida sobre a amostra e deixada em descanso por 15 minutos. Após este período, foram lavados em água corrente e cortados em pequenas tiras. Logo após, o bagaço foi processado em processador doméstico para alimentos (Philco, Mod. PH900) com $500 \mathrm{~mL}$ de água destilada. Em seguida, o excesso de água foi retirado com auxílio de um tecido de nylon fino.

A massa produzida foi espalhada uniformemente em bandeja de polietileno de alta densidade PEAD e levada para secagem em estufa com circulação de ar forçada (Thoth, Mod. 501) a $50{ }^{\circ} \mathrm{C}$ por 30 horas. Após secagem, a massa foi moída em moinho de facas tipo ciclone com peneira 32 Mesh interna (Tecnal, Mod. R-TE-651/2). O pó produzido foi chamado de "Farinha do Mesocarpo de laranja", esta farinha foi em seguida, armazenada em saco plástico para alimentos e mantido sob refrigeração $\mathrm{a}-8^{\circ} \mathrm{C}$ até análises.

A pectina foi extraída com ácido cítrico (Alphatec, P.A ACS). Alíquotas com $5 \mathrm{~g}$ da farinha do mesocarpo foram dissolvidas em $150 \mathrm{~mL}$ da solução aquosa de ácido cítrico nas concentrações avaliadas. As extrações foram realizadas em banho ultratermostático (Solab, Mod. SL-152-I) em diferentes concentrações, temperaturas e tempos.

o planejamento experimental para o rendimento de extração da massa péctica foi determinado seguindo um delineamento composto central rotacional com quatro pontos axiais e três repetições no ponto central, totalizando 15 ensaios través do modelo matemático de Box-Behnken (Tabela 1). Os fatores avaliados para o rendimento de extração foram concentração ácida $\mathrm{Mol} \mathrm{L}^{-1}$, tempo de extração e temperatura, denominadas de variáveis independentes. $O$ rendimento em porcentagem de pectina extraída em cada experimento foi considerado a variável resposta ou dependente. Os ensaios foram realizados em duplicata.

Após a extração ácida, as amostras foram filtradas em tecido fino de nylon, e o sobrenadante armazenado. Ao filtrado, foi adicionado $150 \mathrm{~mL}$ de álcool etílico $95 \%$ (Dinâmica, P.A - ACS). A solução ficou em descanso por 60 minutos na geladeira a $4{ }^{\circ} \mathrm{C}$. Em seguida, a pectina precipitada foi filtrada, e lavada duas vezes com álcool etílico $70 \%(v / v)$ e álcool etílico 95\% (P.A - ACS). Uma terceira 
Tabela 1. Experimento de otimização pelo modelo de Box-Behnken para pectina do bagaço de laranja.

\begin{tabular}{lccc}
\hline Experimento & Conc. ácida $\left(\mathbf{M ~ L ~}^{-1}\right)$ & Tempo $(\mathbf{m i n})$. & Temperatura $\left({ }^{\mathbf{0}} \mathbf{C}\right)$ \\
\hline 1 & 0,50 & 10 & 27,5 \\
2 & 1,00 & 10 & 27,5 \\
3 & 0,50 & 90 & 27,5 \\
4 & 1,00 & 90 & 27,5 \\
5 & 0,50 & 50 & 15,0 \\
6 & 1,00 & 50 & 15,0 \\
7 & 0,50 & 50 & 40,0 \\
8 & 1,00 & 50 & 40,0 \\
9 & 0,75 & 10 & 15,0 \\
10 & 0,75 & 90 & 15,0 \\
11 & 0,75 & 10 & 40,0 \\
12 & 0,75 & 90 & 40,0 \\
13 & 0,75 & 50 & 27,5 \\
14 & 0,75 & 50 & 27,5 \\
15 & 0,75 & 50 & 27,5 \\
\hline
\end{tabular}

Fonte: Autores, 2020.

lavagem foi realizada com acetona (Alphatec, P.A - ACS). Após este processo, a pectina foi desidratada em estufa com circulação de ar forçada a $50{ }^{\circ} \mathrm{C}$ até peso constante, conforme descrito por Munhoz et al. (2010) modificado. O rendimento de pectina obtida nos ensaios foi determinado conforme equação a seguir. Rendimento $(\%)=($ Pectina extraída/Massa farinha)*100.

$\mathrm{O} \mathrm{pH}$ foi determinado conforme proposto por Fernandes et al. (2014) modificado. Uma alíquota de $5 \mathrm{~g}$ de pectina foi acrescida com $100 \mathrm{~mL}$ de água ultrapura, a amostra foi homogeneizada por $5 \mathrm{~min}$. e deixada em descanso por 10 min. A aferição do $\mathrm{pH}$ foi realizado em pHmetro de bancada (Lucadena, Mod. 210P) a $25^{\circ} \mathrm{C}$.

A fração proteica foi determinada em porcentagem de nitrogênio total a partir da pectina do bagaço de laranja, segundo o método de Kjeldahl proposto por Borges et al. (2009). Uma alíquota de 0,250 g de pectina foi digerida em bloco digestor (Novatécnica, Mod. NT352) a $370{ }^{\circ} \mathrm{C}$. O fim da digestão ocorreu com a mudança de cor da solução. Logo em seguida, as amostras digeridas foram levadas para o destilador de nitrogênio (Tecnal, Mod. TE0364) e tituladas. O fator de correção aplicado foi de 6,25 sob o nitrogênio total. A pureza foi determinada conforme equação, Pureza \% $=100$ - teor de proteínas.

As amostras de pectina comercial e da farinha do mesocarpo de laranja nas condições experimentais ótimas foram quantificadas por titulometria, conforme proposto por Fernandes et al. ( 2014). Alíquotas $250 \mathrm{mg}$ de pectina foram umedecidas com $3 \mathrm{~mL}$ de álcool etílico $95 \%$, e solubilizada em $25 \mathrm{~mL}$ de água ultrapura (Milli-Q ${ }^{\circ}$, Mod. RiOs) sob agitação constante em mesa agitadora (Solab, Mod. SL180DT) a $170 \mathrm{rpm}$ por $35 \mathrm{~min}$., sendo em seguida determinado o $\mathrm{pH}$ da solução.

As carboxilas livres dos ácidos anidrogalacturônicos foram neutralizadas com solução aquosa de $\mathrm{NaOH} 0,1 \mathrm{~N}$. As carboxilas esterificadas após saponificação com $10 \mathrm{~mL}$ de solução aquosa de $\mathrm{NaOH}$ na concentração $0,25 \mathrm{~N}$ por 60 min. sob agitação constante. Após este tempo, a solução foi acidificada com $10 \mathrm{~mL}$ de uma solução aquosa de $\mathrm{HCl}$ 0,25 N e novamente neutralizada com solução aquosa de $\mathrm{NaOH} 0,1$ $\mathrm{N}$, obtendo os valores de $\mathrm{mEq}$ de $\mathrm{NaOH}$ referentes as duas carboxilas (livres e esterificadas), respectivamente. Sendo representadas por mEq' e mEq".

Foram calculados a quantidade de massa por $\mathrm{mEq}$ conforme equação $Z$ = (Massa pectina/mEq totais). $O$ teor de resíduos galacturônicos pela equação $A \cup A \%=(17600 / Z)$. Para o teor de metoxilas conforme equação $\mathrm{MeO} \%=\left(\mathrm{mEq}^{\prime \prime}\right.$ x 31 x 100/massa pectina). Para o percentual de ácidos poligalacturônicos de acordo com a equação Fração ácida = (AUA\% + MeO\%). Percentual de açúcares neutros conforme equação Fração neutra = 100 - Fração ácida. E para o grau de esterificação DE\% = (176/31) $\times(\mathrm{MeO} / \mathrm{AUA})$. Para efeito de comparação, também foi realizada a caracterização titulométrica da pectina cítrica comercial.

O experimento através do modelo de Box-Behnken foi realizado em duplicata, e para os experimentos de $\mathrm{pH}$, proteínas, pureza, (Z), (AUA\%), (MeO\%), (FA\%), (FN\%) e (GE\%) foram realizados em triplicata seguido de $( \pm$ ) desvio padrão, apresentado pelas médias obtidas. Os dados de rendimento de pectina obtidos, foram submetidos à análise 
de variância por meio do programa Minitab (versão 19) e os demais, realizados no programa de estatística PAST 3 (versão 3.14, 2019).

\section{RESULTADOS E DISCUSSÃO}

As indústrias devem apresentar produção otimizada produzindo em grande quantidade e garantindo a qualidade do produto final. Com isso, o uso de artifícios matemáticos como o modelo de Box-Behnken pode ser utilizado garantindo uma melhora na otimização em menor tempo, na redução de gastos com reagentes, bem como, menor geração energética, podendo ser empregado nos mais variados processos de extração pécticos (VRIESMANN et al., 2011; PASANDIDE et al., 2017; KAZEMI et al., 2019).

Na Tabela 2, está apresentada a análise de variância para o modelo de extração de pectina da farinha do mesocarpo de laranja.

De acordo com a Tabela 2, o modelo de regressão representou significativamente a relação entre as variáveis independentes e a resposta obtida pelo rendimento com $\mathrm{R}^{2}$ de $91,78 \%, \mathrm{R}^{2}$ (ajustado) de $88,09 \%$ e o $\mathrm{R}^{2}$ (predito) de 79,40\%. Fernandes et al. (2014) através de um modelo de regressão, obtiveram relação entre as variáveis independentes e a reposta com $\mathrm{R}^{2}$ igual a 93\% para pectina da farinha de cenoura.

Na Figura 1, observa-se no diagrama de Pareto o efeito padronizado linear (L) e quadrático (Q) das variáveis: concentração ácida, tempo e temperatura e suas interações sobre o rendimento de extração de pectina da farinha do mesocarpo de laranja.

Os efeitos com valores acima de 2,08 $(P=0,05)$ a direita da linha tracejada, foram estatisticamente significativos (Figura 1). Observa-se que, as variáveis: ácido, tempo e temperatura, e suas interações ácido*ácido, tempo*tempo, ácido*temperatura e temperatura*temperatura apresentaram efeitos significativos para a resposta do rendimento de pectina da farinha do mesocarpo de laranja. Nas interações ácido*tempo e tempo*temperatura não apresentaram influência (positiva) significativa no rendimento. Ainda na Figura 1, observa-se que a variável temperatura apresentou maior resposta quando comparada a concentração ácida e o tempo de extração respectivamente.

Isso infere que, qualquer aumento nas variáveis positivas dentro das faixas avaliadas, surte efeito positivo no rendimento de pectina. Percebe-se que a influência da temperatura foi superior à influência dos efeitos ácido e tempo de extração. No estudo de Menezes Filho et al. (2020) os pesquisadores encontraram resultados próximos ao deste estudo, com efeito de 2,09 ( $P=0,05)$, onde o termo ácido foi superior a temperatura, e o tempo não foi fator de significância para o modelo avaliado. Siqueira et al. (2012) obtiveram efeitos lineares das variáveis temperatura e concentração ácida, e interação tempo de extração e temperatura significativos, para o rendimento de extração da pectina da casca do fruto do pequi. Fertonani (2006) obteve para as variáveis independentes (concentração ácida e tempo de extração) para pectina do bagaço de maçã extraída com ácido nítrico, efeitos lineares significativos e quadráticos não significativos.

Neste estudo é possível observar através da equação (1) de regressão em unidades não codificadas o rendimento mássico de pectina (\%).

Tabela 2. Análise de variância para o modelo de extração de pectina da farinha do mesocarpo de laranja.

\begin{tabular}{lccccc}
\hline Fonte & GL & $\mathbf{S Q}(\mathbf{A j .})$ & $\mathbf{Q M} \mathbf{( A j . )}$ & Valor F & Valor-P \\
\cline { 2 - 6 } Modelo & 9 & 3348,26 & 372,03 & 24,83 & 0,00 \\
Linear & 3 & 1810,57 & 603,52 & 40,28 & 0,00 \\
$\quad$ Ácido & 1 & 518,53 & 518,53 & 34,60 & 0,00 \\
$\quad$ Tempo & 1 & 272,06 & 272,06 & 18,16 & 0,00 \\
$\quad$ Temperatura & 1 & 1019,98 & 1019,98 & 68,07 & 0,00 \\
Quadrado & 3 & 1368,39 & 456,13 & 30,44 & 0,00 \\
$\quad$ Ácido*Ácido & 1 & 707,09 & 707,09 & 47,19 & 0,00 \\
Tempo*Tempo & 1 & 714,16 & 714,16 & 47,66 & 0,00 \\
Temperatura*Temperatura & 1 & 115,46 & 115,46 & 7,71 & 0,01 \\
Interação com 2 Fatores & 3 & 169,30 & 56,43 & 3,77 & 0,03 \\
$\quad$ Ácido*Tempo & 1 & 12,79 & 12,79 & 0,85 & 0,37 \\
$\quad$ Ácido*Temperatura & 1 & 156,47 & 156,47 & 10,44 & 0,00 \\
$\quad$ Tempo*Temperatura & 1 & 0,03 & 0,03 & 0,00 & 0,96 \\
Erro & 20 & 299,69 & 14,98 & - & - \\
Falta de ajuste & 3 & 182,93 & 60,98 & 8,88 & 0,00 \\
Erro puro & 17 & 116,75 & 6,87 & $*$ & $*$ \\
Total & 29 & 3647,95 & - & - & - \\
\hline
\end{tabular}

Fonte: Autores, 2020. 


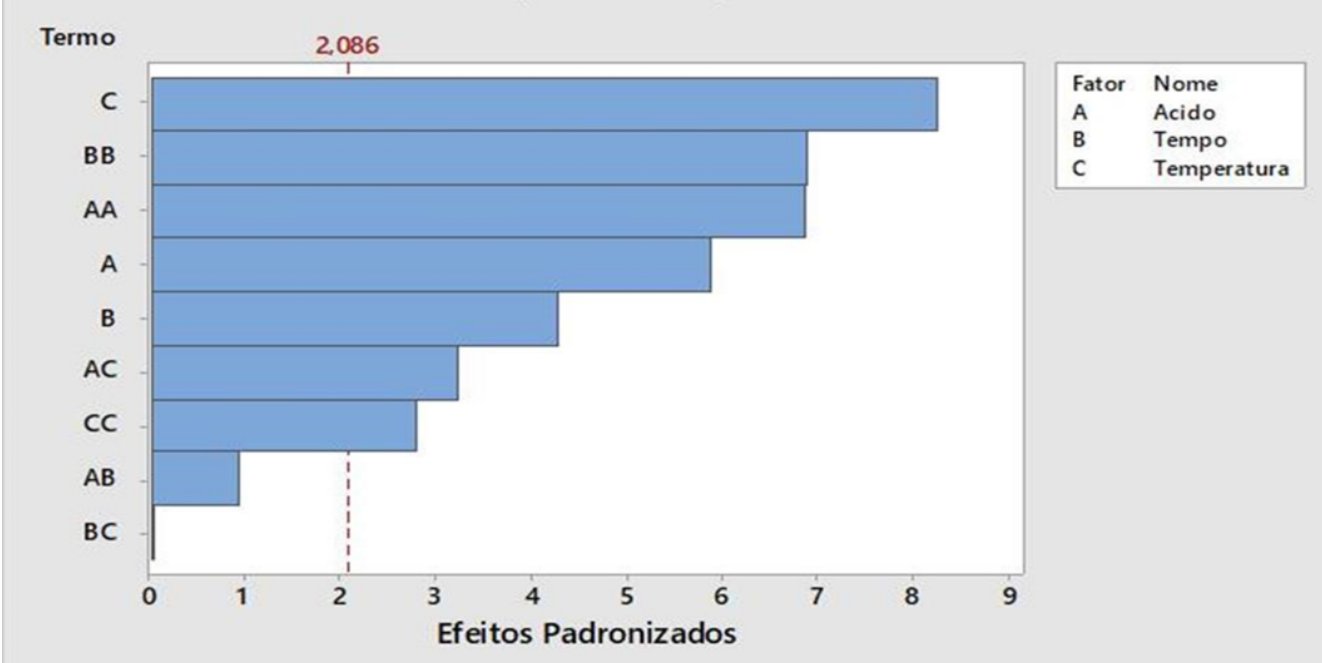

Figura 1. Diagrama de Pareto dos efeitos padronizados para pectina do bagaço de laranja. A resposta é rendimento com efeitos de valores acima da linha tracejada $(2,08)(\mathrm{P}=0,05)$ foram significativos. Linear (L) (ácido, tempo e temperatura), Quadrático (Q) (ácido*ácido, tempo*tempo e temperatura*temperatura), e interação com dois fatores (ácido*tempo, ácido*temperatura e tempo*temperatura). Fonte: Autores, 2020 .

Rendimento\% $=-86,3+212,4$ Ácido + 0,626 Tempo + 0,976 Temperatura - 156,6 Ácido*Ácido - 0,006146 Tempo*Tempo - 0,02531 Temperatura*Temperatura + 0,126 Ácido*Tempo + 1,415 Ácido*Temperatura - 0,00013 Tempo*Temperatura Eq. (1).

Na Figura 2 (A), o modelo da área de superfície nas interações tempo*ácido não apresentou significância para o rendimento péctico com resultado de $\geq 43,64 \%$. Em (B) nas interações temperatura*ácido apresentou maior taxa de rendimento de extração $\geq 48,95 \%$. Já em (C) as interações temperatura*tempo não apresentaram significância para o modelo de extração. Sendo a temperatura*ácido os fatores de significância para este modelo de extração de pectina da farinha do mesocarpo de laranja. 0 mesmo foi observado por Menezes Filho et al. (2020) onde as interações temperatura*ácido para um modelo de área superficial por Box-Behnken na extração de pectina da farinha da entrecasca de melancia. Os pesquisadores obtiveram rendimento entre 44,18 a $44,35 \%$ de pectina extraída.

De acordo com Fernandes et al. (2014) a maior produção de pectina comercial é derivada de bagaços de frutas cítricas como a maçã, com variação de produção entre 20 a $30 \%$. Neste estudo, o processo de otimização apresentou duas possíveis soluções. A 1a solução indica que o ácido cítrico na concentração de $0,88 \mathrm{Mol} \mathrm{L}^{-1}$, com tempo de $59,3 \mathrm{~min}$. e temperatura de $40{ }^{\circ} \mathrm{C}$ apresentou percentagem de rendimento de $49,55 \%$. Já para 2a solução indica que o ácido cítrico na concentração $0,93 \mathrm{Mol} \mathrm{L}^{-1}$, com tempo de 71,09 min. e temperatura de $40{ }^{\circ} \mathrm{C}$ apresentou percentagem de rendimento de $48,43 \%$, sendo superior ao obtido no estudo de Fernandes et al. (2014) por comparação. Com isso, a variação da porcentagem de rendimento entre as duas opções, determina que para indústrias de alimentos que requerem menor tempo de produção e gasto energético, a melhor opção é a 1a que obtêm satisfatório rendimento péctico em menor tempo, com temperatura relativamente baixa, poupando tempo e gasto que são dois dos fatores primordiais em produção que visa menor tempo e maior economia de matéria-prima.

Adib et al. (2017) obtiveram rendimento entre 6,81 a $10,12 \%$ de pectina da casca de romã em um modelo com temperatura de $86^{\circ} \mathrm{C}$, com tempo de 80 min., concentração de ácido nítrico de $20 \mathrm{mmol} \mathrm{L}^{-1}$ e $\mathrm{pH}$ de 1,7. Fernandes et al. (2014) encontraram rendimentos de pectinas entre 1,95 a $14,73 \%$ para a farinha de cenoura, sendo o tempo máximo de $180 \mathrm{~min}$. Os autores ainda obtiveram rendimento de $21,10 \%$ para pectina de maracujá e de $19,68 \%$ para pectina de laranja nas mesmas condições para o experimento com farinha de cenoura.

Zanella (2013) avaliando diferentes temperaturas e $\mathrm{pH}$ de 2,5 obteve no melhor ensaio avaliado rendimento de $38,21 \%$ de pectina na casca da laranja-Pera. Siqueira et al. (2012) a partir da farinha do fruto do pequizeiro obtiveram rendimento péctico entre 14,89 a 55,86\%. Munhoz et al. (2010) avaliaram a pectina das farinhas de polpa e da polpa com casca do fruto da goiabeira, onde obtiveram rendimentos de 7,83 a 13,66\% para a farinha da polpa, e de 5,91 a $12,85 \%$ para a farinha da polpa com casca de goiaba. Todos exceto o trabalho de Siqueira et al. (2012) apresentaram rendimentos inferiores aos obtidos neste estudo para a farinha do mesocarpo de laranja. 

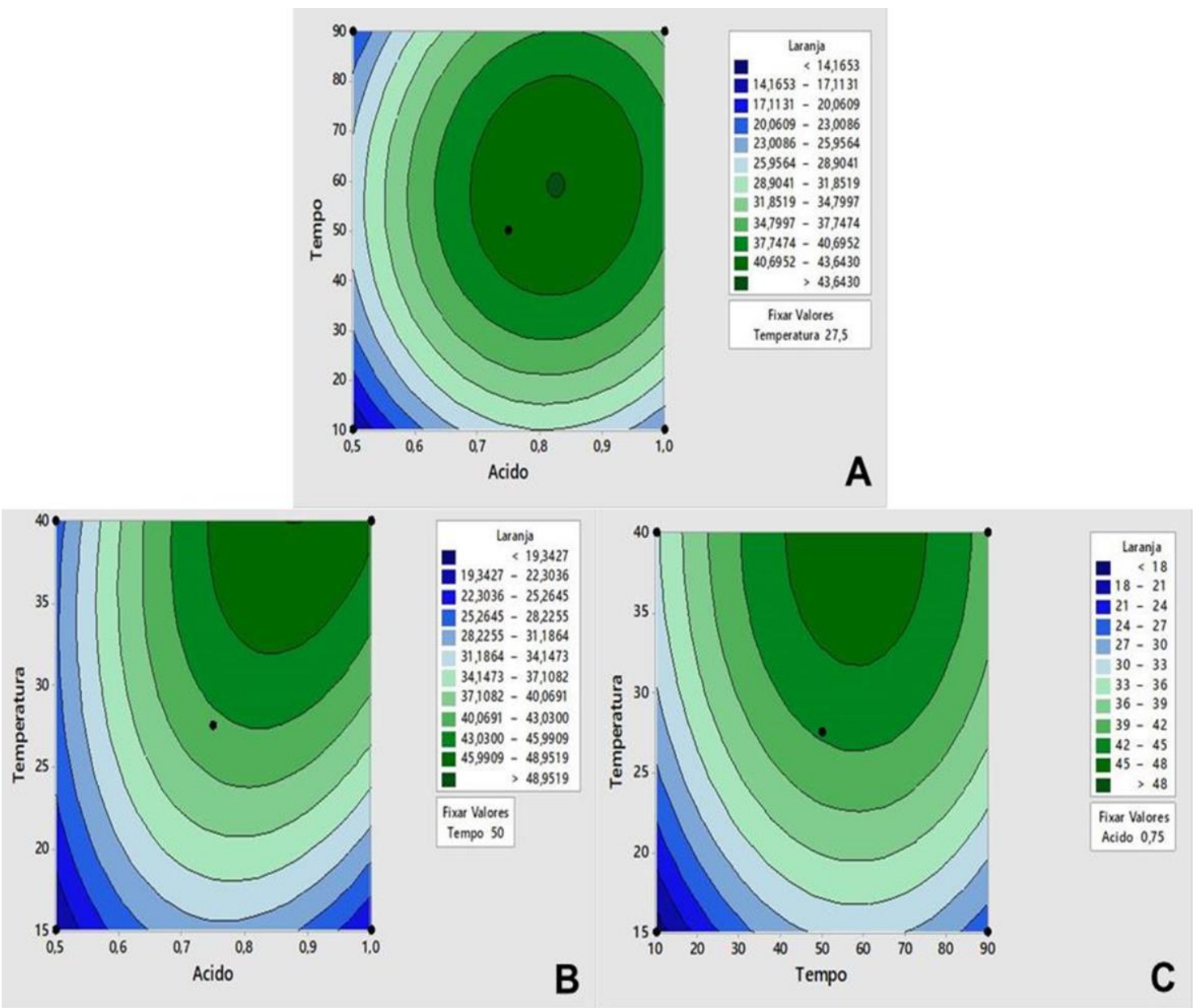

Figura 2. Gráficos de contornos dos rendimentos de extração de pectina de Laranja. Em (A) rendimento*tempo; ácido. Em (B) rendimento*temperatura; ácido e em $(\mathbf{C})$ rendimento*temperatura; tempo. Fonte: Autores, 2020.

A pectina de laranja obtida a partir do experimento de superficie de resposta por Box-Behnken apresentou (AUA\%) de $44,8 \% \pm 0,03$; (MeO\%) 0,7\% \pm 0,06; (FA\%) de $45,4 \% \pm$ 0,04 ; (FN\%) de $54,6 \% \pm 0,03$ e (GE\%) de $8,75 \% \pm 0,02.0 \mathrm{pH}$ da pectina obtida foi de $2,68 \pm 0,04$, proteína igual a $3,47 \% \pm$ 0,05 e grau de pureza de $96,53 \% \pm 0,02$. Comparou-se a pectina obtida da farinha do mesocarpo de laranja com a pectina comercial cítrica onde apresentou $\mathrm{pH}$ de 2,9 $\pm 0,01$; (AUA\%) de 6,6\% \pm 0,04; (MeO\%) de 0,7\% $\pm 0,03$; (FA\%) de $7,3 \% \pm 0,01$; (FN\%) $92,7 \% \pm 0,07$ e grau de esterificação (GE\%) de $59,46 \% \pm 0,08$. Pectinas obtidas a partir da farinha do mesocarpo de laranja com estas características podem ser utilizadas como fibra dietética solúvel na forma de sucos, bebidas, geleias diet e sheiks, pois não afetam a viscosidade do mesmo e aumentam o teor de fibras solúveis do produto (FERNANDES et al., 2014).

Em especial, conforme Yapo et al. (2007) e Sharma et al. (1998) as pectinas de baixo grau de esterificação possibilitam a formação de géis estáveis na ausência de açúcares e na presença de íons metálicos. Já as pectinas de alto grau de esterificação, são menos propícias a alterações de $\mathrm{pH}$, formando assim, géis com pHs entre 2,6 a 6,0 podendo ser utilizadas como espessante e estabilizante de emulsões para a indústria alimentícia.

Adib et al. (2017) encontraram para diferentes variedades de romãs (AUA\%) entre 47,05 a $68,51 \%$, e (GE\%) entre 34,1 a 46,1\%. Maran et al. (2014) obtiveram (AUA\%) de $64,32 \%$ e (GE\%) de $50,14 \%$ para pectina obtida a partir do bagaço de maçã. Fernandes et al. (2014) avaliaram a pectina extraída da farinha de cenoura onde encontraram resultados para (AUA\%) de 45,63\%, (MeO) de 3,49\%, (FA\%) de $81,47 \%$, (FN\%) de $18,52 \%$ e (GE\%) de $24,44 \%$. Zanella (2013) encontrou diferentes porcentagens para (AUA\%) entre 68,52 a $93,64 \%$ o (GE\%) entre 61,03 a $77,39 \%$ para a pectina do mesocarpo de laranja.

E no estudo realizado por Pinheiro et al. (2008), os pesquisadores obtiveram pectina do maracujá com grau de esterificação de 78,59\% em concentração ácida de 0,086\% (ácido cítrico) e tempo de $60 \mathrm{~min}$. Quando comparados aos resultados obtidos neste experimento para pectina da farinha do mesocarpo de laranja, observa-se que o ácido galacturônico está próximo ao observado por Fernandes et al. (2014) para pectina da farinha de cenoura. Valores altos de ácido galacturônico podem estar relacionados diretamente com as temperaturas de secagem e extração péctica. Temperaturas entre 50 a $100^{\circ} \mathrm{C}$ podem degradar por 
hidrólise alguns materiais não pécticos que são misturados com a pectina durante o processo de extração, aumentando a pureza (ELNAWAWI; SHEHATA, 1987).

$\mathrm{O}$ teor de metoxilas obtido neste experimento para pectina da farinha do mesocarpo de laranja está abaixo dos relatados em outros estudos com pectinas. Os altos teores de (FN\%) estão envolvidos na etapa de purificação da pectina com as lavagens em etanol $70 \%$ e $95 \%$ respectivamente. Pode-se inferir que as lavagens não foram bem sucedidas, conforme observado pelo resultado neste estudo, interferindo em outros fatores como no teor de ácido galacturônico.

Essas lavagens conforme Georgiev et al. (2012) removem os açúcares neutros presentes na molécula de pectina, aumentando assim a pureza e o valor do teor de ácido galacturônico. Constenla et al. (2002) afirma que o grau de esterificação GE\% é afetado principalmente pelas condições de secagem da pectina. Possivelmente a baixa porcentagem de GE\% obtido neste estudo foi influenciada negativamente pelo processo de secagem a $50{ }^{\circ} \mathrm{C}$, sendo assim, outros trabalhos deverão ser realizados utilizando temperaturas inferiores a deste estudo.

Reiterando, de acordo com Blanco et al. (2019) e Adib et al. (2017) o grau de esterificação está intimamente ligado no peso molecular, $\mathrm{pH}$ e na força iônica para formação de um gel com boas características. Quanto maior o grau, maior serão as interações hidrofóbicas pelo gel apresentando maior força de interação intermolecular.

\section{CONCLUSÕES}

O processo de extração de pectina de laranja com ácido cítrico através da otimização no experimento em área superficial pelo modelo de Box-Behnken apresentou rendimento entre $48 \%$ e $49 \%$. O experimento de superfície de resposta para o rendimento de pectina de laranja apresentou duas soluções com variação da concentração ácida e tempo de extração, e temperatura fixa, sendo a primeira opção a mais indicada para indústrias de alimentos.

A pectina obtida nas melhores condições de extração apresentou porcentagem de grau de esterificação abaixo de $50 \%$, sendo consideradas de baixo grau de esterificação. No entanto o teor de ácido galacturônico da pectina da farinha do mesocarpo de laranja foi maior que a pectina comercial, e em especial, o alto grau de pureza obtido neste estudo. Pectinas obtidas a partir da farinha do mesocarpo da laranja com as características apresentadas neste estudo podem ser utilizadas após prévio estudo como fibra dietética solúvel na forma de sucos e Sheiks, bem como incorporada em metais com princípios de floculação em tratamento de afluente e efluente.

\section{AGRADECIMENTOS}

Os autores agradecem ao Instituto Federal de Educação, Ciência e Tecnologia Goiano, Campus Rio Verde pela bolsa de iniciação científica; aos Laboratórios de Química Tecnológica, Produtos Naturais e Nutrição Animal; aos órgãos de fomento em pesquisa, CAPES, CNPq, FINEP e a FAPEG pela bolsa de mestrado para o primeiro autor.

\section{REFERÊNCIAS}

ABID, M., CHEIKHROUHOU, S., RENARD, C. M. G. C., BUREAU, S., CUVELIER, G., ATTIA, H., AYADI, A. M. Characterization of pectins extracted from pomegranate peel and their gelling properties. Food Chemistry, v. 215, p. 318-325, 2017.

AMAL, A. M., EMAN, A. M. M., NAHLA, S. Z. Fruit flavored yoghurt: chemical, functional and rheological properties. International Journal of Environmental \& Agriculture Research, v. 2, n. 5, p. 57-66, 2016.

BATISTA, J. A., TANADA-PALMU, P. S., GROSSO, C. R. F. Efeito da adição de ácidos graxos em filmes à base de pectina. Ciência e Tecnologia de Alimentos, v. 25, n. 4, p. 781788, 2005.

BLANCO, J. C., CAICEDO, M. L., CARO, M. P., CENTENO, J. M., RODRÍGUEZ, M. H. Elaboración de uma película plástica biodegradable a partir del almidon de yuca y pectina. Revista CLIC, v. 1, n. 1, p. 1-3, 2019.

BORGES, A. M., PEREIRA, J., LUCENA, E. M. P. Caracterização da farinha de banana verde. Revista Ciência e Tecnologia de Alimentos, v. 29, n. 2, p. 333-339, 2009.

BRAVERMAN, J. B. S., BERK, Z. Braverman's introduction to the Biochemistry of foods. Elsevier, New York, 1976.

CANTERI, M. H., MORENO, L., WOSIACKI, G., SCHEER, A. P. Pectina: da matéria-prima ao produto final. Polímeros, $v$. 22, n. 2, p. 149-157, 2012.

CONSTENLA, D., PONCE, A. G., LOZANO, J. E. Effect of pomace drying on apple pectin. LebensmittelWissenschaft Und-Technologie-Food Science and Technology, v. 35, n. 3, p. 216-221, 2002.

ELNAWAWI, S. A., SHEHATA, F. R. Extraction of pectin from egyptian orange peel - factors affecting the extraction. Biological Wastes, v. 20, n. 4, p. 281-290, 1987.

FERNANDES, R. V. B., MENDES, F. Q., BOTREL, D. A., DA CUNHA, M. C. Otimização do processo de extração e caracterização química de pectina de cenoura. Magistra, v. 26, n. 2, p. 115-123, 2014.

FERTONANI, H. C. R. Estabelecimento de um modelo de extração ácida de pectina de bagaço de maçã. (Dissertação de Mestrado). Universidade Estadual de 
Ponta Grossa.

MAY, C. Industrial pectins: Sources, production and applications. Carbohydrate Polymers, v. 12, p. 79-99, 1990.

GANCZ, K., ALEXANDER, M., CORREDIG, M. In situ study of flocculation of whey protein-stabilized emulsions caused by addition of high methoxyl pectin. Food Hydrocolloids, v. 20, n. 2-3, p. 293-298, 2006.

GEORGIEV, Y., OGNYANOV, M., YANAKIEVA, I., KUSSOVSKI, V., KRATCHANOVA, M. Isolation, characterization and modification of citrus pectins. Journal of Bioscience and Biotechnology, v. 1, n. 3, p. 223-233, 2012.

KAZEMI, M., KHODAIYAN, F., LABBAFI, M., HOSSEINI, S. S., HOJJATI, M. Pistachio green hull pectin: Optimization of microwave-assisted extraction and evaluation of its physicochemical, structural and functional properties. Food Chemistry, v. 271, p. 663-672, 2019.

KORSTEN, L., TAVERNER, P. Citrus. In: Rees, D., Farrell, G. (Ed.). Crop Post-Harvest: Science and Technology Perishables. 1, Blackwell Publishing Ltd., 2012. Cap. 4, p. 43-87.

LARA-ESPINOZA, C., CARVAJAL-MILLÁN, E., BALANDRÁNQUINTANA, R., LÓPEZ-FRANCO, Y., RASCÓN-CHU, A. Pectin and pectin-based composite materials: Beyond food texture. Molecules, v. 23, n. 4, p. 942, 2018.

LIMA, C. M. G., SANTOS, J. J., MIRANDA, R. F., VIANA, R. B. B., SANTOS, M. S., BARBOSA, E. A. Aceitabilidade de geleia de pimenta dedo-de-moça com pectina da casca do pequi. The Journal of Engineering and Exact Sciences, v. 3, n. 6, p. 786-791, 2017.

MARTINS, W. T. R., NARDOQUE, S. O circuito produtivo de laranja na microrregião geográfica de Jales-SP. Ateliê Geográfico, v. 14, n. 1, p. 69-88, 2020.

MENEZES FILHO, A. C. P., DE SOUZA, J. C. P., CASTRO, C. F. S. Produção, rendimento e caracterização físico-química de pectina a partir da entrecasca de melancia (Citrullus lanatus): otimização por experimento Box-Behnken. Revista Agrária Acadêmica, v. 3, n. 1, 2020.

MUNHOZ, C. L., SANJINEZ-ARGANDOÑA, E. J., SOARES JÚNIOR, M. S. Extração de pectina de goiaba desidratada. Revista Ciência e Tecnologia de Alimentos, v. 30, n. 1, p. 119-125, 2010.

PAIVA, E. P., LIMA, M. S., PAIXÃO, J. A. Pectina: propriedades químicas e importância sobre a estrutura da parede celular de frutos durante o processo de maturação. Revista Iberoamericana de Polímero, v. 10, n. 4, p. 196211, 2009.

PAGÁN, J., IBRAZ, A., LLORCA, M., PAGÁN, A., BARBOSACÁNOVAS, G. V. (2001). Extraction and characterization of pectin from stored peach pomace. Food Research International, v. 34, n. 7, p. 605-612, 2001.
PASANDIDE, B., KHODAIYAN, F., MOUSAVI, Z. R., HOSSEINI, S. S. Optimization of aqueous pectin extraction from Citrus medica peel. Carbohydrate Polymers, v. 178, p. 27-33, 2017.

PINHEIRO, E. R., SILVA, I. M. D. A., GONZAGA, L. V., AMANTE, E. R., TEÓfILO, R. F., FERREIRA, M. M. C., AMBONI, R. D. M. C. Optimization of extraction of high-ester pectin from passion fruit peel (Passiflora edulis flavicarpa) with citric acid by using response surface methodology. Bioresource Technology, v. 99, n. 13, p. 5561-5566, 2008.

REN, J-N., HOU, Y-Y., FAN, G., ZHANG, L-L., LI, X., YIN, K., PAN, $S-Y$. Extraction of orange pectin based on the interation between sodium caseinate and pectin. Food Chemistry, v. 283, p. 265-274, 2019.

REZZADORI, K., BENEDETTI, S. Proposições para valorização de resíduos do processamento do suco de laranja. In: $2^{\text {nd }}$ International Workshop Advances in Cleaner Production. Key elements for a sustainable world: Energy, water and climate change. São Paulo, Brasil, maio $20^{\text {th }}-22^{\text {nd }}, 2009$.

SABERIAN, H., HAMIDI-ESFAHANI, Z., GAVLIGHI, H. A., BARSEGAR, M. Optimization of pectin extration from orange juice waste assisted by ohmic heating. Chemical Engineering and Processing: Process Intensification, v. 117, p. 154-161, 2017.

SHARMA, S. K., LIPTAY, A., LE MARGUER, M. Molecular characterization, physico-chemical and functional properties tomato fruit pectin. Food Research International, v. 30, n. 7, p. 543-547, 1998.

STORRER, D., MEIRELES, K. H., PERLY, M. D., LIMAS, R. S., MATTANNA, P. Desenvolvimento de pão com adição de farinha de bagaço de laranja: Análises sensoriais, físicoquímicas e microbiológicas. Revista Eletrônica Biociências, Biotecnologia e Saúde, v. 9, n. 18, p. 43-50, 2017.

SIQUEIRA, B. S., ALVES, L. D., VASCONCELOS, P. N., DAMIANI, C., SOARES JÚNIOR, M. S. Pectina extraída de casca de pequi e aplicação em geleia light de manga. Revista Brasileira de Fruticultura, v. 34, n. 2, p. 560-567, 2012.

TASIC, L. A biomassa da laranja e seus subprodutos. Revista Virtual de Química, v. 9, n. 1, 2017.

VASCO-CORREA, J., ZAPATA, A. D. Z. Enzymatic extraction of pectin from passion fruit peel (Passiflora edulis $f$. flavicarpa) at laboratory and bench scale. LWT, v. 80, p. 280-285, 2017.

VRIESMANN, L. C., TEÓFILO, R. F., PETKOWICZ, C. L. O. Optimization of nitric acid-mediated extraction of pectin from cacao pod husks (Theobroma cacao L.) using response surface methodology. Carbohydrate Polymers, v. 84, n. 4, p. 1230-1236, 2011

ANELLA, K. (2013). Extração da pectina da casca da laranjapera (Citrus sinensis L. Osbeck.) com solução diluída de 
ácido cítrico. Dissertação mestrado. Universidade Estadual de Campinas.

YAPO, B. M., ROBERT, C., ETIENNE, I., WATHELET, B., PAQUOT, $M$. Effect of extration conditions on the yield, purity and surface properties of sugar beet pulp pectin extracts. Food Chemistry, v. 100, n. 4, p. 1356-1354, 2007.

Submissão: 08/11/2020

Aprovado para publicação: 24/11/2020 